\title{
LA REPRESENTACIÓN DE LA PATA DE CABRA EN UN TEATRO DE PROVINCIAS: VALENTÍA O TEMERIDAD
}

\author{
THE REPRESENTATION OF LA PATA DE CABRA \\ Sergio SUÁREZ RAMÍREZ \\ Universidad de Valladolid \\ sergio.suarez@uva.es \\ Ángel SUÁREZ MUÑOZ \\ Universidad de Extremadura \\ asuarez@unex.es
}

IN A THEATER OF PROVINCES: COURAGE OR TEMERITY

Resumen: La ciudad de Badajoz tuvo durante el siglo XIX una intensa actividad teatral, superior a la que ha podido constatarse a través de las crónicas periodísticas de la época, que permiten un seguimiento cronológico a partir de 1860. Antes, es posible rescatar episodios sueltos a través de la documentación encontrada en archivos municipales y provinciales. Uno de esos episodios revela la osadía del director de una compañía para escenificar La pata de cabra en el teatro de una provincia, precario y con escasos recursos escénicos, animado por la conocida afición teatral de esta población, arriesgando su economía y reputación.

Palabras clave: La pata de cabra. Teatro. Siglo XIX. Badajoz. Magia. Compañía teatral.

Abstratc: The city of Badajoz had an intense theatrical activity during the
nineteenth century, superior to that which has been verified through the
journalistic chronicles of the time, which allow chronological monitoring
from 1860 . Before, it is possible to rescue loose episodes through the
documentation found in municipal and provincial archives. One of those
episodes reveals the boldness of the director of a company to stage the 
kickstand in the theater of a province, precarious and with scarce scenic resources, encouraged by the well-known theatrical hobby of this population, risking its economy and reputation.

Key Words: La pata de cabra. Theater. XIX Century. Badajoz. Magic. Theater Company.

\section{INTRODUCCIÓN}

Tanto los estudios sobre el teatro representado en la ciudad de Badajoz durante el siglo XIX, como los estudios similares desarrollados en otras ciudades durante ese mismo periodo, han utilizado las crónicas aparecidas en la prensa de la época como hilo conductor, lo que, en muchos casos, ha permitido elaborar una cronología muy completa y fiable acerca de lo que realmente sucedió. También han permitido resaltar elementos sociológicos que rodearon la actividad teatral, derivados de los comentarios que los cronistas dejaban en las páginas de los periódicos, muchas veces más propios de la crónica social que de la específica o técnicamente teatral.

Sin embargo, la prensa en la ciudad de Badajoz, sobre todo durante la primera mitad del siglo XIX, es muy escasa y está muy fragmentada. Eso ha dificultado hacer un estudio continuado como los que ya se han publicado y que abarcan desde 1860 hasta la finalización del siglo.

La ausencia de esta fuente documental, que permita hacer un seguimiento pormenorizado de las funciones teatrales celebradas en la ciudad, no significa que no existiera actividad teatral. Otros documentos (cartas, informes, registros notariales, etc.) encontrados en los archivos municipales y provinciales testimonian precisamente lo contrario: que sí la había. Es verdad que son episodios inconexos, pero confirman una actividad escénica muy intensa, variada y de calidad.

En este artículo se quiere destacar uno de esos episodios: la representación de La pata de cabra en la ciudad de Badajoz, en el año 1840 , por cuanto significó una apuesta arriesgada, pero a la vez decidida y valiente, de la compañía dirigida por Miguel Rivelles, dadas las precarias condiciones del teatro y las exigencias escénicas de la obra.

La elección de este episodio, y no otro, viene motivada por la abundante documentación recuperada en torno al mismo; también permite 
dar a conocer pormenores interesantes sobre las prácticas escénicas de la época y contribuye a realzar la importancia de esta ciudad de provincias en el panorama escénico del siglo XIX, lo que la convertiría con el paso de los años en lugar obligado de parada para las compañías teatrales profesionales con destino Lisboa, ya fuera en la ruta procedente de Madrid o en la trazada por el sur, con origen en Sevilla.

\section{EL TEATRO PRINCIPAL O DEL CAMPO DE SAN JUAN}

En estudios previos (Suárez Muñoz, 1996, 1997, 2002 y 2003 producto de su tesis de doctorado1_-; Suárez Muñoz y Suárez Ramírez, 2002 y 2006; Suárez Ramírez y Suárez Muñoz, 2018), se ha documentado la apertura de un teatro justo a comienzos del siglo XIX en la ciudad de Badajoz. El que había sido Hospital de la Piedad, situado muy cerca de la Iglesia Catedral y también a poca distancia del Hospital San Sebastián (el más importante de la ciudad en ese siglo), como consecuencia de la desamortización de Mendizábal, pasa a manos de un particular, Jaime Carles y Busquet. Este hacendado vecino de la ciudad lo compró por 90.000 reales de vellón, equivalente a unos 337 euros actuales y, conocedor de la falta de un edificio dedicado al teatro (el último Corral de Comedias situado en la calle Dómine Galindo, actual Donoso Cortés, había sido derribado en 1731), decide habilitarlo para teatro, quedando operativo a finales de agosto de 1800. Debió valorar también, sin duda, su ubicación: el centro de la ciudad, a escasos cien metros del Ayuntamiento de entonces y de ahora; y en medio del itinerario o paseo principal utilizado habitualmente por la ciudadanía: Plaza de España (Campo de San Juan entonces) a Paseo de San Francisco, zona de expansión y recreo.

La importancia de esa compra y su transformación en teatro solo se ha podido valorar con el paso de los años y los estudios realizados. Gracias a esa decisión se pudo desarrollar y consolidar una afición teatral bastante intensa y constante, capaz de propiciar muchos años después (concretamente en 1864) el proyecto de construcción de un teatro propiamente dicho, también en ese itinerario y colindante con el Paseo

\footnotetext{
${ }^{1}$ Defendida en la UNED, bajo la dirección de José Romera Castillo, en 1994, que puede leerse completa en https://www2.uned.es/centro-investigacion-SELITEN@T/pdf/angelsuarez.pdf [07/01/2020].
} 
de San Francisco, más acorde con la afición existente y con el progreso urbanístico y social de la ciudad, con intención de competir con otras capitales del país, al menos en lo que a lo teatral se refiere. Así, el treinta de octubre de 1886 se inauguró el Teatro López de Ayala que, con más o menos dificultades, ha logrado sobrevivir hasta nuestros días. Aquella decisión, tomada en 1800, ha marcado la historia de la ciudad durante más de doscientos años. Hoy no sería la misma sin ese teatro. Ni su estructura urbanística ni sus actividades socioculturales tampoco serían las mismas.

Pero, evidentemente, un hospital que se habilita de manera precipitada como teatro no podía responder ni a la infraestructura, ni a la seguridad, ni a las condiciones mínimas necesarias, exigidas para albergar con normalidad funciones teatrales. Y, sin embargo, echa a rodar y acogerá como espacio prioritario las representaciones escénicas que se organizan en la ciudad, tanto por grupos de aficionados como por compañías profesionales, hasta la apertura del Teatro López de Ayala en la fecha que hemos indicado.

En un protocolo notarial encontrado en el Archivo Histórico de Badajoz, identificado con el número treinta y siete, redactado y firmado por el notario Lorenzo Mendoza y fechado a veintiocho de abril de 1864, se hace constar la comparecencia de don Florencio Martín y Castro, reclamando la herencia dejada por Josefa Carles Goicoechea, fallecida el doce de febrero de ese año, y referida al teatro de su propiedad. Todo el expediente se inscribió en el Registro de la Propiedad de Badajoz, tomo séptimo, folio doscientos cuarenta y cuatro con número de finca quinientos noventa y nueve. Lo más interesante de todo el expediente, sin duda, es la descripción de la finca donde se encontraba ubicado el Teatro del Campo de San Juan (Anexo I) y algunos pormenores de su interior:

La Casa Teatro se halla situada en la Plaza de la Constitución de esta Capital, llamada en lo antiguo Campo de San Juan, no estaba marcada con ningún número, pero en la actualidad tiene en dicha plaza y puerta principal del edificio el número ocho y en otra puerta accesoria de la calle de Santa Catalina el uno. Por la derecha entrando hace esquina a dicha calle de Santa Catalina en la que tiene una fachada que mide veinte y una varas; por la izquierda, linda con la casa número siete de dicha plaza de la Constitución propia de don Carlos Márquez y con la casa número seis de la misma plaza, perteneciente a los herederos de don Juan Crespo García; y por la espalda, con casa de don Juan Romero Falcón, que se 
halla señalada con el número tres de la referida calle de Santa Catalina. El edificio se halla situado sobre un área plana irregular, pero semejante a un paralelogramo que mide trece varas y tercia de ancho por treinta de largo. Compónese el local de un salón de entrada, de dieciséis varas de largo por cinco de ancho; del Teatro propiamente dicho, cuyo patio o platea mide diez y seis varas de largo por ocho y media de ancho, por término medio; el foro o palco escénico con los vestuarios tiene once varas de ancho por trece de largo; sobre el salón de entrada ecsiste [sic] una planta alta de igual ancho que éste y seis varas más de largo, que se halla dividida en varias habitaciones; sobre los vestuarios y en uno de los lados del foro hay también planta alta insignificante, estando el resto del edificio en una sola planta.

Desde su habilitación este teatro, situado en el Campo de San Juan, se convirtió en lugar frecuente para funciones de todo tipo (escénicas, bailes, conciertos, prestidigitación, cuadros disolventes, etc.) compartidas, aunque mínimamente, con otros dos escenarios regentados por aficionados: el Liceo de Artesanos y el Conservatorio de la Orquesta Española.

El Teatro del Campo de San Juan, conocido también como Teatro Principal, no se caracterizó desde su inauguración por sus buenas condiciones, como ya se ha referido. A través de los comentarios aparecidos en la prensa ${ }^{2}$ algunos años después, es fácil hacerse una idea de las condiciones que presentaba este teatro en el momento en que se contempla la posibilidad de representar La pata de cabra. Para El Avisador de Badajoz en su número cuarenta y tres de dos de noviembre de 1862 este teatro "no reúne las condiciones que se requieren en los de su clase" y, detallando un poco más, comenta que no reúne las circunstancias necesarias, "ni por su estructura interior, ni por su capacidad" para una capital de provincia como Badajoz. Mucha debió ser la resignación acumulada durante tantos años entre los aficionados al teatro, para entender que, ahora, se reclame que "es menester pensar en otro que lo sustituya con ventaja, debiendo permitir el doble de la cabida que hoy tiene"; en cuanto a la acústica y su decoro interior deben ser lo que "la esperiencia [sic] tiene acreditado para los edificios de su clase". También a través de la Crónica de Badajoz del tres de abril de 1864 se conocen aspectos relacionados con la deficiente iluminación,

\footnotetext{
${ }^{2}$ Consultada en la sección de hemeroteca de la Biblioteca pública Bartolomé J. Gallardo de Badajoz. Actualmente, también se puede consultar en https://prensahistorica.mcu.es/es/inicio/inicio.do [28/02/2020].
} 
pues si no fuera por "las fúlgidas estrellas de las beldades hechiceras que concurren a nuestro coliseo, seguramente viviríamos en tinieblas". En la misma publicación, pero unos meses después, concretamente el día ocho de diciembre, se añade que "el frío que reina en el teatro es capaz de helar no solo las palabras"; y cinco días después, insistiendo en la iluminación, se da cuenta del temor fundado que existe de quedarse a oscuras el día menos pensado, por eso "llevamos nuestra correspondiente vela de esperma y una caja de fósforos . En definitiva, volviendo al número del tres de abril, en esa casa, llamada teatro, "todo es malo, antiguo y de mal gusto", teniendo todo un aspecto vulgar y pobre. En multitud de ocasiones se rogó al dueño del teatro para que introdujera en él algunas reformas, no solo para que presentara mejor aspecto, sino para que las localidades fueran algo más cómodas y el frío no se dejara sentir de un modo tan intenso. Esas reformas contribuirían a que la concurrencia fuera mayor, y mayores por lo tanto las cantidades que recibiría por el arriendo el propietario del local. Además, las empresas que lo arrendaran podrían ver recompensados con más facilidad los esfuerzos que emplearan en agradar al público. Este teatro limitaba mucho las obras que eran escenificadas en él, obligando a las compañías a realizar esfuerzos, a veces poco recompensados, para hacer más variado su repertorio.

\section{LA PATA DE CABRA EN LOS REPERTORIOS DEL TEATRO DEL SIGLO XIX}

Todo lo vence el amor o La pata de cabra (comedia de magia y de gran espectáculo en tres actos) fue una adaptación del melodrama cómico de Ribié y Martainville, titulado Le pied de mouton, estrenado en París en 1806, que realizó Juan de Grimaldi y que dio a conocer mediante el montaje que preparó para el Teatro del Príncipe de Madrid en febrero de 1829. Grimaldi era por entonces una persona que se desenvolvía bien en los ambientes culturales de la capital tras su llegada a España. El éxito alcanzado en su estreno le impulsó a firmar como suya la primera edición de esta obra, tal y como han comentado estudiosos de esta obra y de este autor, como Caldera (1982, 1984, 2001), Gies (1986) o Ribao Pereira (2006), entre otros.

La pata de cabra fue sin duda el drama más popular en la primera mitad del XIX, como consecuencia principalmente del espectáculo que 
aseguraba. Consiguió atraer al público a los teatros en un momento en que se encontraban sumidos en una gran crisis económica y casi en la ruina. Como acertadamente ha señalado Gies (1986: 48) "su popularidad trajo dinero a los cofres de los empresarios y creó un público acostumbrado a presenciar las extravagancias del drama romántico".

Esta obra, en poco tiempo, compitió y superó en fama a dramas muy reconocidos, como Don Álvaro o la fuerza del sino del Duque de Rivas, El trovador de García Gutiérrez o Don Juan Tenorio de José Zorrilla, por citar algunos; tampoco le restaron éxito otras obras con las que compartió cartelera, como A Madrid me vuelvo o El casamiento por convicción de Bretón de los Herreros, La huérfana de Bruselas de Grimaldi, La villana de la Sagra de Tirso de Molina, El asombro de Jerez, Juana la Rabicortona de José Cañizares, ni piezas también de magia como El mágico de Astracán de Valladares de Sotomayor, entre otras.

Si su estreno fue en Madrid, también otras ciudades tuvieron el privilegio de poder ver representada en sus teatros esta obra tan espectacular por su aparato escénico. De norte a sur y de este a oeste, recorrió toda la geografía nacional. Desde Palma de Mallorca (Mas i Vives, 1986) hasta Jerez de la Frontera (Álvarez Hortigosa, 2009)33 o desde Santander (Gutiérrez Sebastián, 2009) hasta Barcelona (Radigales i Babí, 1998), entre otros lugares, está documentada la puesta en escena de esta obra, lo que dice mucho en favor de los teatros en los que se representó.

Como es ya conocido, la obra muestra las peripecias en las que se ve envuelto don Juan para poder casarse con doña Leonor, recluida por don Lope, su severo tutor, hasta que decida aceptar al pretendiente que le ha buscado: don Simplicio. Don Juan quiere suicidarse, momento en el que se le aparece Cupido, que le entrega un amuleto de la suerte, una pata de cabra, con la promesa de que conseguirá la felicidad eterna al lado de doña Leonor. Para ello, debe viajar a Zaragoza con el propósito de enfrentarse al pretendiente, don Simplicio. Siempre ayudado por Cupido, don Juan consigue librarse de diversos apresamientos a los que le conduce su deseo de estar con doña Leonor; incluso, Cupido le ayudará a vencer a Vulcano, aliado a su vez de don Simplicio, el pretendiente. Finalmente, don Lope,

\footnotetext{
${ }^{3}$ La tesis completa puede leerse en la web del Centro de Investigación de Semiótica Literaria, Teatral y Nuevas Tecnologías, dirigido por el profesor José Romera Castillo: https://www2.uned.es/ centro-investigacion-SELITEN@T/pdf/TesisHistoria\%20delTeatroenJerez.pdf [07/01/2020]
} 
resignado, acepta el matrimonio de don Juan y doña Leonor. La obra acaba con el reconocimiento de don Simplicio de que "todo lo vence el amor".

Se ha señalado que La pata de cabra dio una importancia enorme a la escenografía; resultaba muy característico el cuidado que se otorgó a las acotaciones, en las que el autor describía lugares, momentos, sonidos, gestos, movimientos e, incluso, procedimientos escénicos concretos. Para Gómez Alonso, en el drama romántico:

[...] es más importante ver que oír (sobresalen los rasgos visuales frente a los literarios). Por tanto, la comedia de magia puede ser entendida como subliteratura: lo espectacular se antepone al texto, con lo que las "máquinas" utilizadas interesan más al espectador que el diálogo y los propios personajes. Para incrementar el deseo de satisfacción por parte del público, el espectáculo se completaba con instrumentos ópticos y mecánicos. El objetivo fundamental, como el de cualquier espectáculo parecido, era la atracción, que en el caso de las comedias de magia se valía de promover el horror (de forma divertida) y provocar sorpresa. Para disimular el ruido en los cambios producidos por las poleas y grúas, se aprovechaba la utilización de música (Gómez Alonso, 2002: 96).

Por su parte, Ribao Pereira afirma que, aunque la comedia de magia continuó cosechando éxitos a lo largo del siglo XIX, pese a la prohibición y decadencia del género, evidenciadas ya desde las últimas décadas del siglo anterior, insistió en la utilización de recursos escénicos para llamar la atención del público:

El efectismo de la puesta en escena, el empleo de maquinaria aérea, las mutaciones complejas a la vista del público, los juegos de luces y sonidos, el recurso a lo onírico, lo horroroso, o lo mágico en escena, siguen siendo denominadores comunes de un género que evoluciona al mismo ritmo de la sociedad en que se manifiesta (Ribao Pereira, 2006: 5).

No se puede ignorar que Grimaldi recurrió a Jean-Baptiste Blanchard para que trabajara junto a él en los teatros madrileños del Príncipe y de la Cruz, convirtiéndose así en:

el escenógrafo de los primeros dramas románticos representados en España e introductor, en la escena española, de los planteamientos estéticos vigentes en París y del empleo escénico de recursos procedentes de los espectáculos ópticos, con los que se hallaba muy familiarizado 
(Pinedo, 2015: 104).

Por su parte, Bretón de los Herreros en El Correo Literario y Mercantil de Madrid del día diecinueve de noviembre de 1832 también se refirió a los decorados que ambientaban al sacrificio de la cabra, a poco de comenzar el acto primero:

Es una creación muy propia del genio distinguido y de las luces que han dado tanto crédito al Sr. Blanchard. Aquellos grupos errantes de visiones, espectros, ensueños, pesadillas y cuantos horrores y desconciertos traza la humana fantasía al través del sueño y de las tinieblas, causan un efecto sorprendente, y dan un prestigio verdaderamente mágico á la misteriosa ceremonia que en torno suyo se ejecuta.

Por eso, volviendo a Pinedo (2015: 103), no es descabellado creer que "La escenografía teatral, los espectáculos ópticos y otras expresiones artísticas crean un nuevo observador en el siglo XIX". En el diario madrileño El Correo del día dos de septiembre de 1831 se comentaba asimismo que:

[...] cuando se anuncia La Pata de Cabra, el más rudo de los espectadores sabe muy bien que no va a ver una obra clásica de literatura, que no va a ver una comedia [...] va a divertirse y a reír poderosamente por espacio de tres horas; asiste a una función teatral que halaga sus sentidos.

Para Gies (1986), la popularidad de La pata de cabra emanaba del propio espectáculo, que reunía hasta treinta y cinco efectos de magia: desde vuelos de objetos y personas, hasta transformaciones, apariciones y desapariciones, cambios de escenario (once escenarios diferentes y doce cambios de escena), efectos que además de misteriosos, mezclaban elementos cómicos con ambiente romántico (paisajes lúgubres, bosques, cuevas iluminadas, tempestades, brujería, etc.). Todo ello exigía la participación de expertos tramoyistas que trabajaran rápidamente en el manejo del escenario, así como de eficientes escenógrafos y decoradores.

Igualmente, Gómez Alonso comenta que el gusto por las comedias de magia, cuyo apogeo se extendió desde finales del siglo XVIII hasta mediados del XIX, está relacionado con los gustos caprichosos de los espectadores que, por entonces, muestran predilección: 
por lo exótico, fantástico y macabro. Durante las mismas fechas aparecen referencias a anuncios de exhibición de personas deformes (gigantes, malformaciones). En el desarrollo de las obras se intenta generar mundos de ensueño y pesadilla, acordes con las representaciones pictóricas del momento (Gómez Alonso, 2002: 94).

Consiste en dar espectáculo, en complacer las peticiones o gustos del público que, en definitiva, es quien paga y quien, de esa forma, mantiene a las compañías y a las empresas teatrales. Checa Beltrán (1992), poniendo como ejemplo el teatro de Lope de Vega, los romances de Moratín o las películas actuales, ha recalcado que en las comedias de magia primaba, por encima de cualquier otra cosa, el espectáculo, porque lo que de verdad interesaba era la recaudación que se obtuviera en cada representación.

Los grandes teatros se podían dotar de recursos para la utilización de efectos en las comedias de magia, máxime teniendo en cuenta que el espectáculo dependía en gran parte de ellos: decorados en los que destacaran los telones, tramoyas con movimiento, juegos de sombras en las paredes, presencia de seres sobrenaturales (fantasmas, ninfas...), que revivieran (esqueletos) o autómatas, juegos pirotécnicos e hidráulicos... En definitiva, múltiples recursos al servicio de un fin concreto: la diversión, el espectáculo y la asistencia, cuanto más numerosa, mejor.

Es razonable pensar que los principales teatros de Madrid, como el de la Cruz o del Príncipe, dispusieron de esos recursos, estando preparados para este tipo de espectáculo. En cambio, un teatro de provincia, como el de Badajoz, difícilmente lo estaría. Recordemos que el palco escénico medía once varas de largo por trece de ancho, algo menos de 100 metros cuadrados; lo que, a tenor de lo publicado en la prensa de la época, equivalía a "muy reducido". Respecto a las decoraciones "todo era malo, antiguo y del peor gusto". En definitiva, se disponía de una infraestructura bastante escasa para un montaje o representación escénica tan exigente.

Sin embargo, en 1839 recorre algunas localidades de la geografía extremeña la compañía teatral que dirigen Miguel Rivelles y Fulgencio Faquineto, integrada por el elenco de artistas que aparecen en el programa que fue difundido (Anexo II). Aunque sus actuaciones concluyeron al llegar el Carnaval de 1840, debieron ser bastante exitosas, porque hemos encontrado en el Archivo Municipal de la ciudad una serie de escritos 
en los que Miguel Rivelles se interesa por conocer las costumbres sobre precios y reservas de palcos en el teatro de la ciudad de Badajoz con la finalidad de obsequiar al público, al inicio de la nueva temporada, con la representación de La pata de cabra. Especialmente interesante es el escrito, fechado el treinta y uno de agosto de 1840, que dirige el director de la compañía teatral al alcalde (Anexo III), solicitando autorización para un incremento en el precio de las localidades. Empieza diciendo que:

[...] deseoso de complacer en un todo a los havitantes [sic] de esta Ciudad a quienes está sumamte agradecido; además de estarles presentando en escena composiciones de las más modernas, trata de que se ejecute con todo su aparato corresponte la gran Comedia de magia titulada: La Pata de Cabra $\mathrm{p}^{\mathrm{a}}$ lo cual, venciendo cuantas dificultades ofrece un Teatro tan desprovisto como lo es este, va a desprenderse de unos cuantos miles de rr [sic] $\mathrm{p}^{\mathrm{a}}$ que vean la antedicha comedia, tal como se ha ejecutado en Madrid (en cuanto a la maquinaria).

Y concluye:

Para reportar el gasto de esta espero de la bondad de V.S.S. me permita pueda poner la entrada gral [sic] a $4 \mathrm{rr}$ [sic] las lunetas a $3=$ Los palcos los y plateas a $16=$; los palcos 2 os segundos y plateas a $12=y$ las sillas $a$ 2 = atendiendo a los grandes gastos qe voy a hacer y que no dudo quedarán complacidos, pues no se omite nada de cuanto marca su Autor.

Ese mismo día recibe la respuesta favorable desde el Ayuntamiento con la única condición de que "han de dar un cuarto por entrada para atender a la reparación de la Alameda de la Puerta de Palmas".

Aunque, como se ha indicado, la compañía teatral concluyó sus funciones al llegar el Carnaval de 1840, algo debieron percibir Miguel Rivelles y Fulgencio Faquineto en la población de Badajoz y en su afición al teatro, porque la temporada de invierno precedente no ha sido nada rentable para sus intereses. El caso es que, ya desde la primavera, sopesan la posibilidad de permanecer en Badajoz y continuar con sus funciones teatrales. Así, el once de abril Miguel Rivelles dirige un escrito al señor presidente de la Junta de Caridad del Hospital San Sebastián (Anexo IV) para que acepte negociar el pago del cuarto por entrada a que tiene derecho sobre las funciones que se llevan a cabo en el teatro, confirmando que ha solicitado el permiso correspondiente "para qe mi compa Dramática pueda 
egercer [sic] sus funciones en esa capital durante el presente año cómico [sic] en cualquiera delas [sic] épocas [sic] de él, pues quiero acer [sic] la feria, la primavera y temporada de ynvierno". En ese mismo escrito reconoce que es:

Publico [sic] y notorio es qe en la última temporada dada en esa se aperdido [sic] y no poco, pero vaya para cuando se gana". Reconoce que la exención de pago por entrada que solicita aliviará sus cargas, porque "ademas [sic] de qe se paga por la casa teatro mas [sic] qe vale, y es la quinta parte de todos los palcos y lunetas, un cuarto por entrada, otro pa el Hospital, un palco Prãl, dos lunetas y cinco Entradas, conqe si a mas [sic] se toma $S$. E. los dos palcos es ir atrabajar [sic] para ellos...

Se pueden calificar como osadía o temeridad las intenciones de los señores Rivelles y Faquineto para escenificar en Badajoz La pata de cabra, dadas las condiciones del teatro y las exigencias de la obra. Miguel Rivelles, el director que interviene como representante de la compañía, alude a los sacrificios que está dispuesto a hacer para "que vean la antedicha comedia, tal como se ha ejecutado en Madrid (en cuanto a la maquinaria)".

No es desacertado pensar el efecto ilusionante que esta promesa despertaría en gobernantes y en el público aficionado al teatro de la localidad y su comarca, pues no desconocerían lo que se había publicado unos años antes en el Diario de Avisos de Madrid, concretamente el diez de octubre de 1832, cuando se detalla la tecnología utilizada en la función teatral de La pata de cabra:

En efecto, se ha reformado toda la maquinaria, añadiendo varias transformaciones nuevas enteramente y de suma visualidad de que antes carecía [...] de suerte que La pata de Cabra, conservando su gracioso y aplaudido texto, se puede decir diversificada casi en su totalidad en cuanto a su aparato escénico, juegos mecánicos y demás. Un espectáculo, que tan prodigiosa concurrencia ha conseguido en sus repetidisimas y siempre aplaudidas representaciones, debía presentarse al público con innovaciones: se ha tratado, pues, de que estas fuesen dignas del público a quien se dedicaban: Ningún gasto, ningún trabajo se ha omitido para dar $a$ La Pata de Cabra por segunda vez el interés privilegiado de la novedad; y se espera que cuantos la han visto y aplaudido la volverán a ver a y a aplaudir. 
Se desconoce con exactitud en qué condiciones se encontraba el teatro en 1840, pero sabemos cómo estaba en 1837 y qué reformas se proponen como ineludibles en 1841. Y, entre un año y otro, la representación de la obra por la compañía que dirigen Miguel Rivelles y Fulgencio Faquineto. Precisamente, el día veintisiete de abril de 1841 el arquitecto municipal, Valentín Falcato, remite un escrito al Ayuntamiento (anexo V). En su informe dice haberlo inspeccionado, tal y como ya lo hizo cuatro años antes:

en el día de ayer y en su consecuencia debo manifestar que igual reconocimto practiqué en Marzo del año de 1837 en que informé sobre la necesidad de hacer una reforma de algunas partes del Pavimento q. constituyen las galerías de los Palcos Tertulia o Cazuelas al paso que creía de urgente necesidad el que se apuntalasen todos los puentes que reciven [sic] los pares y asimismo los canes de Madera que vuelan de los Contra Fuertes sostenidos por tornapuntas ensambladas en forma y en resumen que sin estos reparos no podría responderse de la seguridad de este edificio; principalmte en días de grande concurrencia. En el practicado en el día de ayer encuentro que no se hizo todo cuanto queda referido, como se previno por la autoridad de V.S.; sin duda por no haverse [sic] berificado ][sic] segundo reconocimto para cerciorarse de quedar egecutado [sic], $y$ en consecuencia se haya la mayor parte de los antedichos pabimentos [sic] sin la renovación referida, así en sus maderas como en el Solado de Ladrillo, no estando en perfecta armonía las Tornapuntas y pies berticales [sic] que se colocaron para apoyo de los puentes y canes y de aquí ineficaz la resistencia que haya de oponerse a el empuje desproporcionado que sufra la línea de menor fuerza.

Concluye su informe diciendo:

Por lo tanto, creo de absoluta necesidad la reposición de algunos de los pares y puentes que forman los referidos pabimentos [sic] en donde se ha manifestado la caries, el doble alfagiado asi en los corredores como en los palcos, forrando estos además por la parte inferior con tela para ebitar [sic] la caída de los Ladrillos que se desprenden, pues que de esto resultan así la seguridad de las personas como la decencia y ornato: recorrer y asegurar el ensamblado de los pies derechos y tornapuntas y colocar las que faltan totalmente. Conciliando para esto que el tiempo de la duración de estas obras no impida los trabajos de la Comp ${ }^{a}$ Dramática nise [sic] defraude al público de esta diversión.

La Techumbre del Edificio que es una de las partes principales de su 
seguridad no puede ser reconocida sin lebantar [sic] la tela que forma el cielo raso y cerciorarse del estado de las cavezas [sic] de los maderos que empotran en los cercos cuya operación requiere tiempo para que sea echa [sic] en debida forma.

El Ayuntamiento obligó al dueño del teatro, entonces Ventura Muñoz, a acometer las obras sugeridas. De tal calado debieron de ser que no estuvieron concluidas hasta dos años después (1843), cuando los peritos nombrados al efecto por la institución municipal remitieron su informe (anexo VI):

De Badajoz a diez y nueve de Abril de mil ochocientos cuarenta y tres: ante el Sr. Alcalde primero Constitucional, parecieron los peritos Pedro Rodríguez y Antonio Brazas, quienes bajo del cargo $q^{\mathbf{0}}$ tienen aceptado y jurado, y de nuevo aceptan y juran caso necesario Dijeron: Que han reconocido con la mayor escrupulosidad y detenimiento las obras de reparación egecutadas [sic] en el Edificio Teatro de esta Capital, las cuales han encontrado hechas con toda solidez y seguridad no habiendo observado cosa $q^{o}$ pueda amenazar sin perjuicio conocido a los concurrentes a los espectáculos públicos que en dho [sic] edificio se representen. Que así es la verdad en descargo de sus juramentos hechos en el que y esta su declaración leída que les fue, se afirmaron y ratificaron y la firmaron con rúbrica de que certifico = Pedro Rodrigz. Rúbrica. Antonio Brazas Galán. Rúbrica.

Es decir, la representación de La pata de cabra, si finalmente se llegó a verificar, se hizo en un teatro precario, pequeño, desprovisto de los mínimos requisitos exigidos en infraestructura escenográfica y, sobre todo, inseguro, especialmente en funciones con numerosa asistencia de público.

Ninguna documentación se ha encontrado que lleve a pensar que la representación fuera suspendida. No existe ningún escrito de las autoridades que prohibiera dicha representación. Solo se conserva el informe acerca de las precarias condiciones del teatro antes de la representación anunciada (1837) y otro después (1841), indicando que ninguna reforma se había introducido de las entonces recomendadas. Y, sin embargo, sí existe una abundante documentación sobre las intenciones, expresadas por uno de los directores de la compañía (Miguel Rivelles), para llevar adelante la representación, constituida por la solicitud correspondiente, la petición de autorización para subir los precios de las localidades con que compensar 
los gastos, la demanda de información acerca de la costumbre existente de reservar palcos a determinadas autoridades o la solicitud de exención del pago de un cuarto de real por entrada. Demasiadas gestiones y trámites como para pensar que solo fue un proyecto, un amago o una mera intención.

\section{CONCLUSIONES}

Es una lástima que no se conserve la prensa de estos años que, como hemos indicado, es muy irregular e intermitente, para saber con algunos detalles cómo transcurrió la representación de La pata de cabra en un teatro que, antes y después de la fecha de representación, presentaba unas condiciones inadecuadas hasta el punto de peligrar la seguridad de los espectadores.

Lo cierto es que, a la vista de la documentación encontrada, hay motivos para creer que la compañía de Rivelles y Faquineto se atrevió, contribuyendo a dignificar el teatro representado en la ciudad durante el siglo XIX.

Por este mismo escenario, tan precario y limitado, pasaron años después figuras como Enrico Tamberlick o Emma Nevada, quienes, camino de Lisboa, hicieron paradas en la ciudad de Badajoz y, al mismo tiempo que descansaban del largo viaje, obtenían unas ganancias complementarias.

La apuesta y el riesgo asumido por tantos artistas y multitud de compañías teatrales para actuar en un teatro con tantas carencias contribuyen a resaltar la importancia de la ciudad de Badajoz en los circuitos teatrales del siglo XIX, que ya se ha documentado en algunas publicaciones anteriores: el eje Madrid-Lisboa siempre tuvo, en su recorrido por el sur, a Badajoz como paso previo al cruce fronterizo, con procedencia previa bien desde Cáceres o bien desde Sevilla.

Se ha pretendido rescatar un nuevo episodio documentado, que permita añadir elementos para la reconstrucción de la historia del teatro representado durante el siglo XIX.

\section{REFERENCIAS BIBLIOGRÁFICAS}

ÁlVAREZ HORTIGOSA, F. (2009). Historia del teatro en Jerez de la Frontera durante la segunda mitad del siglo XIX. Tesis doctoral. 
Cádiz: Universidad de Cádiz. Puede leerse en https://www2. uned.es/centro-investigacion-SELITEN@T/pdf/TesisHistoria\%20 delTeatroenJerez.pdf [07/01/2020].

CALDERA, E. (1982). "La última etapa de la comedia de magia". En Actas del VII congreso de la Asociación Internacional de Hispanistas, G. Bellini (ed.), vol. II, 247-253. Roma: Bulzoni.

(1984). "La pata de cabra y Le pied de mouton". En Studia historica et philologica in honorem M. Batllori, VV. AA., 567-575. Roma: Instituto Español de Cultura.

(2001). El teatro español en la época romántica. Madrid: Castalia.

CHECA BELTRÁN, J. M. (1992). "La comedia de magia en la crítica neoclásica y romántica". En La comedia de magia y de santos, AA. VV., 383-394. Madrid: Ensayos Júcar.

GIES, D. T. (1986). Edición, introducción y notas a "La pata de cabra". Roma: Bulzoni.

GÓMEZ ALONSO, R. (2002). "La comedia de magia como precedente del espectáculo fílmico". Historia y Comunicación Social 7, 89107.

GUTIÉRREZ SEBASTIÁN, R. (2009). "Retazos del teatro popular en el Santander decimonónico". Siglo diecinueve 15, 81-102. Se ha consultado la versión digitalizada, sin página, de la Biblioteca Virtual Miguel de Cervantes: http://www.cervantesvirtual.com/ obra/retazos-del-teatro-popular-en-el-santander-decimononico/ [10/02/2020].

MAS I VIVES, J. (1986). El teatre a Mallorca a l'època romántica. Barcelona: Publicacions de l'Abadía de Monstserrat.

PINEDO, C. (2015). "Escenografía y espectáculos ópticos: Jean-Baptiste Blanchard". Episkenion 3/4, 103-119.

RADIGALES I BABÍ, J. (1998). Els origens del gran Teatre del Liceu (1837-1847). De la plaça de Santa Anna a la Rambla: història del Liceu Filharmonic d'Isabel II o Liceu Filodramàtic de Barcelona. Barcelona: Publicacions de l'Abadía de Montserrat.

RIBAO PEREIRA, M. (2006). De magia, manuscritos y ediciones: Todo lo vence amor o La pata de cabra (1829-1841). Vigo: Universidad de Vigo.

SUÁREZ MUÑOZ, A. (1997). El Teatro en Badajoz: 1860-1886. Cartelera y Estudio. Madrid: Támesis. 
(1996). "El teatro en la ciudad de Badajoz en el siglo XIX. Los comienzos". Revista de Estudios Extremeños (Badajoz: Diputación Provincial) LII.1, 33-49.

(2002). El Teatro López de Ayala. El teatro en Badajoz a finales del siglo XIX [1887-1900]. Mérida: Editora Regional.

(2003). Entre bambalinas. Estampas teatrales. Badajoz: Caja de Badajoz.

SUÁREZ MUÑOZ, A. y SUÁREZ RAMÍREZ, S. (2002). “Espectáculos parateatrales en Badajoz en el siglo XIX (hasta 1886)". Signa 11, 257-296. Versión digitalizada por la Biblioteca Virtual Miguel de Cervantes, sin página: http://www.cervantesvirtual.com/obravisor/signa-revista-de-la-asociacion-espanola-de-semiotica-5/ $\mathrm{html} / 025 \mathrm{dabac}-82 \mathrm{~b} 2-11 \mathrm{df}$-acc7-002185ce6064_26.html [02/03/2020].

(2006). "El teatro clásico del Siglo de Oro en Badajoz (1860-1900)".

Signa 15, 85-96. Disponible en línea: http://revistas.uned.es/index. php/signa/article/view/6127/5860 [28/02/2020].

SUÁREZ RAMÍREZ, S. y SUÁREZ MUÑOZ, A. (2018). "Los incendios como amenaza de los teatros. El otro incendio del teatro López de Ayala en Badajoz y las circunstancias excepcionales que amenazaron su restauración y supervivencia". Signa 27, 10651093. Disponible en línea: http://revistas.uned.es/index.php/signa/ article/view/18662 [28/02/2020]. 


\section{ANEXOS}

ANEXO I. Descripción de la casa teatro del Campo de San Juan, conocido como Teatro Principal. Transcripción del documento incluido en el Legajo número 24 de los Fondos de la Audiencia. Protocolo notarial. Archivo Histórico de Badajoz.

La Casa Teatro se halla situada en la Plaza de la Constitución de esta Capital, llamada en lo antiguo Campo de San Juan, no estaba marcada con ningún número, pero en la actualidad tiene en dicha plaza y puerta principal del edificio el número ocho y en otra puerta accesoria de la calle de Santa Catalina el uno. Por la derecha entrando hace esquina a dicha calle de Santa Catalina en la que tiene una fachada que mide veinte y una varas; por la izquierda, linda con la casa número siete de dicha plaza de la Constitución propia de don Carlos Márquez y con la casa número seis de la misma plaza, perteneciente a los herederos de don Juan Crespo García; y por la espalda, con casa de don Juan Romero Falcón, que se halla señalada con el número tres de la referida calle de Santa Catalina. El edificio se halla situado sobre un área plana irregular, pero semejante a un paralelogramo que mide trece varas y tercia de ancho por treinta de largo. Compónese el local de un salón de entrada, de dieciséis varas de largo por cinco de ancho; del Teatro propiamente dicho, cuyo patio o platea mide diez y seis varas de largo por ocho y media de ancho, por término medio; el foro o palco escénico con los vestuarios tiene once varas de ancho por trece de largo; sobre el salón de entrada ecsiste [sic] una planta alta de igual ancho que éste y seis varas más de largo, que se halla dividida en varias habitaciones; sobre los vestuarios y en uno de los lados del foro hay también planta alta insignificante, estando el resto del edificio en una sola planta. 


\title{
ANEXO II. Composición de la Compañía que actuó en Badajoz en la temporada 1839/1840. Imagen obtenida del Legajo número 231. Ar- chivo Municipal de Badajoz.
}

\author{
COMPOSICIÓN DE LA COMPANIÍA QUE ACTUÓ EN BADAJOZ EN LA TEMPORADA 1839/40
}

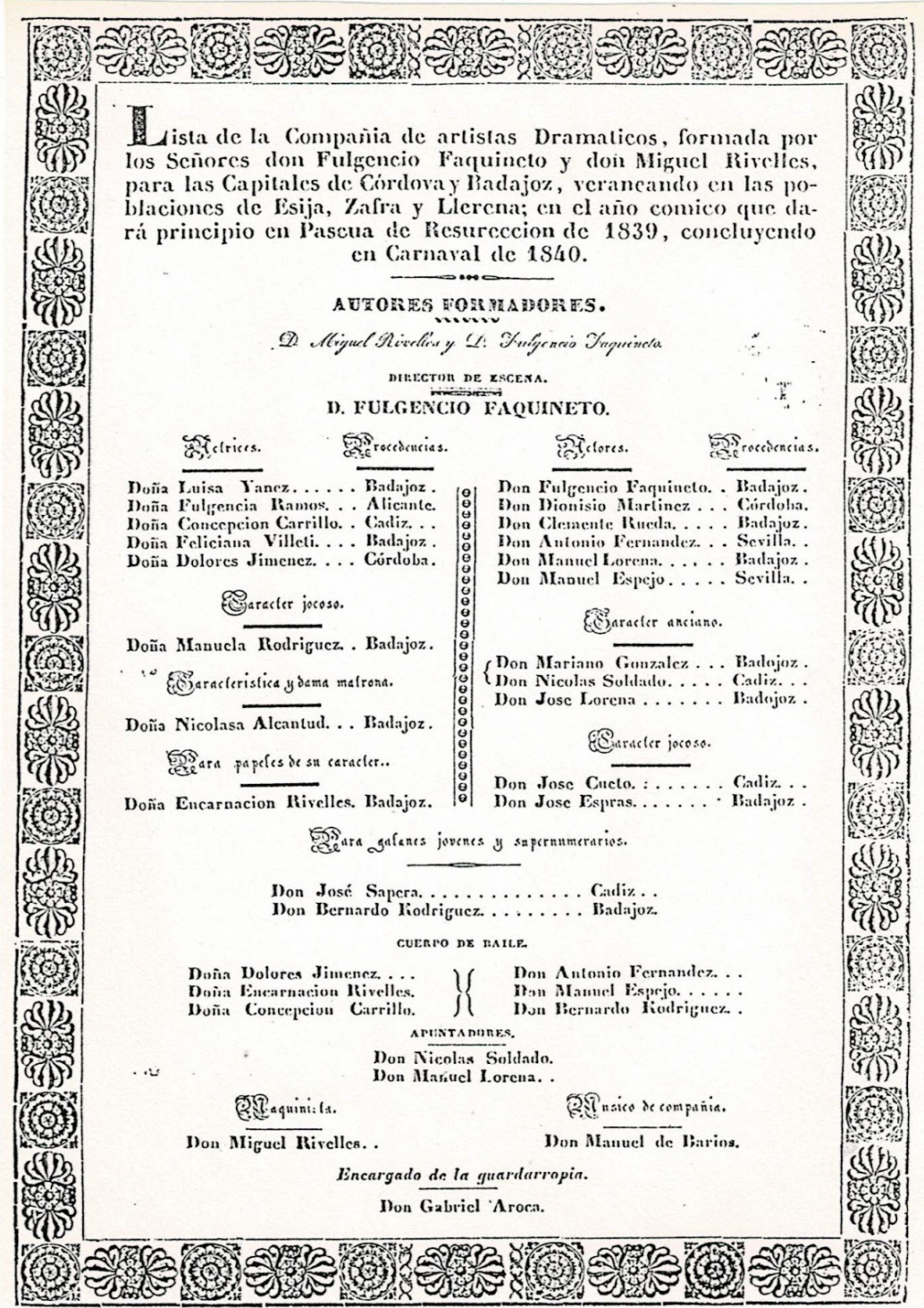




\begin{abstract}
ANEXO III. Escrito de Miguel Rivelles, dirigido al alcalde de Badajoz, solicitando permiso para representar La pata de cabra. Transcripción del documento incluido en el Legajo 231. Archivo Municipal de Badajoz.
\end{abstract}

Ilmo Sr. Ayuntamto de esta Capital

Miguel Ribelles autor de la comp ${ }^{\mathrm{a}}$ de Artistas dramáticos a V.S.S. con el más alto respeto hace presente que, deseoso de complacer en un todo a los havitantes [sic] de esta Ciudad a quienes está sumamte agradecido; además de estarles presentando en escena composiciones de las más modernas, trata de que se ejecute con todo su aparato corresponte la gran Comedia de magia titulada: La Pata de Cabra $p^{\mathrm{a}}$ lo cual, venciendo cuantas dificultades ofrece un Teatro tan desprovisto como lo es este, va a desprenderse de unos cuantos miles de rr [sic] $\mathrm{p}^{\mathrm{a}}$ que vean la antedicha comedia, tal como se ha ejecutado en Madrid (en cuanto a la maquinaria). Para reportar el gasto de esta espero de la bondad de V.S.S. me permita pueda poner la entrada gral [sic] a $4 \mathrm{rr}$ [sic] las lunetas a $3=$ Los palcos 1 os y plateas a 16 $=$; los palcos 20 segundos y plateas a $12=$ y las sillas a $2=$ atendiendo a los grandes gastos qe voy a hacer y que no dudo quedarán complacidos, pues no se omite nada de cuanto marca su Autor $=$

A V.S.S. suplico me conceda las referidas subidas. Gracia qe espero merecer de la bondad de V.S.S. cuya vida gde [sic] el cielo muchos añ [sic]. Badajoz 31 de agosto de $1840=$ Miguel Ribelles. Rúbrica

Badajoz 31 de agosto de 1840 .

Se concede a D. Miguel Ribelles Autor de la Compañía Dramática de esta Capital la subida de precios que solicita y fija en su anterior petición única y esclusivamente [sic] para la representación de la Comedia titulada "La Pata de Cabra", pero no se entienda este aumento respecto las localidades abonadas o que se abonasen y es preciso circunstanciar de que han de dar un cuarto por entrada para atender a la reparación de la Alameda de la Puerta de Palmas. Póngase en conocimto del Sr. Jefe Político esta disposición $\mathrm{p}^{\mathrm{a}}$ que no tenga efecto sin su superior aprobación $=$ Así lo acordó el Ayuntamto en Cabildo de hoy.

C.P. Manuel Lindo. Rúbrica

Gerónimo Rodz [ilegible]. Rúbrica 


\begin{abstract}
ANEXO IV. Escrito dirigido al señor presidente de la Junta de Caridad del Hospital San Sebastián para que acepte negociar el pago del cuarto por entrada a que tiene derecho sobre las funciones que se llevan a cabo en el Teatro. Transcripción del documento incluido en el Legajo 231. Archivo Municipal de Badajoz.
\end{abstract}

Sr. Dn. Manuel Molano. Badajoz

Caceres [sic] 11 abril 1840

Muy S. mío: después de saludarle con todo respeto paso a decirle como [sic] el Sr. de Regino entregara el Memorial por el cual solicito la Licencia para qe mi compa Dramática pueda egercer [sic] sus funciones en esa capital durante el presente año cómico [sic] en cualquiera delas [sic] épocas [sic] de él, pues quiero acer [sic] la feria, la primavera y temporada de invierno [sic]. Espero qe sera [sic] despachado como deseo, pues siempre asido [sic] lo mismo.

Espero qe hara [sic] V. el favor, ya qe es V. presidente de la junta de caridad del Hospital de San Sebastián, qe el cuarto por Entrada [sic] qe tiene de drecho [sic] sobre la casa teatro, y qe probablemente [sic] pagare [sic] yo por ser una de las clausulas [sic] qe en la contrata pone el dueño, qe se govierne [sic] por un tanto mensual o diario según [sic] mas [sic] acomode a la junta, qe como son tantos los gastos qe en sí tiene ese teatro qe es necesario todo para poder salir adelante. al [sic] mismo tiempo cuenta ese piadoso establecimiento con una casa segura y fija y sin gastos de recaudación.

Publico [sic] y notorio es qe en la última temporada dada en esa se aperdido [sic] y no poco, pero vaya para cuando se gana, el motivo de recordar esto es qe el Señor capitán General de estas provincias disfruta dos palcos en uno, qe esta mandado por el gobierno qe se pague toda clase de localidad qe se ocupe por las autoridades tanto siviles [sic] como militares y qe en la susodicha temporada S. E. lo aocupado [sic] o lo atenido [sic] cerrado y no adado [sic] mas [sic] que ocho napoleones, o sean 152 rs. y lo qe adado [sic] a los Beneficiados en sus días cuando le han llevado su papeleta de seda, lo qe no tiene nada qe ver en el pago delos [sic] palcos, y aviendole [sic] reclamado su importe, pues tenía qe dar cuentas, dijo qe avía [sic] una orden Real en qe decía qe permaneciesen los palcos delos [sic] Generales asta [sic] segunda orden, como estavan [sic] anteriormente. pero [sic] me 
parece inposible [sic] y no puede ser, qe el govierno [sic] aquel ni este, ni ninguno pueda, ni hay mandado qe los Señores capitanes Generales tengan palco sin pagarlo, no siendo propiedad por acción ala [sic] fundación del teatro, pero no en el qe el dueño es absoluto y como atal [sic] lo subdarrenda [sic] acualquiera [sic] autor o empresario, baje [sic] ese supuesto, y el de qe las Leyes todas aseguran y guardan las propiedades de todos, espero qe para lo sucesivo se me dé el drecho [sic] qe sobre ellos tengo según contrata, guardando por mi lo mandado por el govierno [sic] y si es qe de drecho [sic] tiene S. E. el palco sin retribución alguna espero se me hara [sic] saber para qe el dueño del teatro me lo rebaje de lo qe pago. Esto mismo hago cuenta de decir en un recurso al Ylte. Ayunto, pero hantes [sic] quiero consultarlo con V. pues asta [sic] bochornoso me es el pensarlo y mas [sic] siendo Dn. Santiago de Mendes Vigo el qe lo disfruta, pero son cosas de corporación y no puedo prescindir de ello, ademas [sic] de qe se paga por la casa teatro mas [sic] qe vale, y es la quinta parte de todos los palcos y lunetas, un cuarto por entrada, otro pa el Hospital, un palco Prãl, dos lunetas y cinco Entradas, conqe si a mas [sic] se toma S. E. los dos palcos es ir atrabajar [sic] para ellos, yo creo qe no es justo y ninguna Ley lo puede mandar ni ninguna clase de govierno [sic] quisiera qe se governara [sic] sin dar pasos qe fuesen bochornosos, pues soy enemigo de ellos y mas [sic] contra una lera autoridad, pero me es sensible, yo espero de su bondad sera [sic]) el medio de arreglarlo y qe no pierda la corporación qe descansa en el celo de su lera autoridad local municipal.

Siento infinito tener V. incomodar su atención, pero confiado en su amistad se atomado [sic] esta libertad su afmo SSS qe [ilegible] Miguel Ribelles. Rúbrica.

\section{ANEXO V. Informe de Valentín Falcato sobre carencias observadas en el teatro tras la visita realizada y que atentan contra la seguridad de los asistentes, dirigido al señor alcalde de la ciudad. Transcripción del documento incluido en el Legajo 231. Archivo Municipal de Badajoz.}

Consecuente a el oficio de V.S. fha 23 del que rige en el que se servía decirme pasase a reconocer el Teatro Público de esta Ciudad para informar sobre su estado de seguridad. $\mathrm{V}^{\mathrm{a}} \mathrm{S}^{\mathrm{a}}$. Lo he verificado en el día de ayer y en su consecuencia debo manifestar que igual reconocimto practiqué en Marzo del año de 1837 en que informé sobre la necesidad de hacer una 
reforma de algunas partes del Pavimento q. constituyen las galerías de los Palcos Tertulia o Cazuelas al paso que creía de urgente necesidad el que se apuntalasen todos los puentes que reciven [sic] los pares y asimismo los canes de Madera que vuelan de los Contra Fuertes sostenidos por tornapuntas ensambladas en forma y en resumen que sin estos reparos no podría responderse de la seguridad de este edificio; principalmte en días de grande concurrencia. En el practicado en el día de ayer encuentro que no se hizo todo cuanto queda referido, como se previno por la autoridad de V.S.; sin duda por no haverse [sic] berificado [sic] segundo reconocimto para cerciorarse de quedar egecutado [sic], y en consecuencia se haya la mayor parte de los antedichos pabimentos [sic] sin la renovación referida, así en sus maderas como en el Solado de Ladrillo, no estando en perfecta armonía las Tornapuntas y pies berticales [sic] que se colocaron para apoyo de los puentes y canes y de aquí ineficaz la resistencia que haya de oponerse a el empuje desproporcionado que sufra la línea de menor fuerza.

Por lo tanto, creo de absoluta necesidad la reposición de algunos de los pares y puentes que forman los referidos pabimentos [sic] en donde se ha manifestado la caries, el doble alfagiado así en los corredores como en los palcos, forrando estos además por la parte inferior con tela para ebitar [sic] la caída de los Ladrillos que se desprenden, pues que de esto resultan así la seguridad de las personas como la decencia y ornato: recorrer y asegurar el ensamblado de los pies derechos y tornapuntas y colocar las que faltan totalmente. Conciliando para esto que el tiempo de la duración de estas

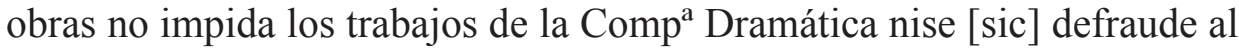
público de esta diversión.

La Techumbre del Edificio que es una de las partes principales de su seguridad no puede ser reconocida sin lebantar [sic] la tela que forma el cielo raso y cerciorarse del estado de las cavezas [sic] de los maderos que empotran en los cercos cuya operación requiere tiempo para que sea echa [sic] en debida forma.

Todo lo que pongo en conocimto de V.S. para que silo [sic] estima conbente dicte las providencias que su celo por el vien [sic] del público le sugieren. Dios guē a V.S. ms ans. Badajoz 27 de abril de 1841. Valentín Falcato. Rúbrica 


\begin{abstract}
ANEXO VI. Los peritos Pedro Rodríguez y Antonio Brazas Galán comparecen para informar sobre el reconocimiento de las obras de mejora del Teatro que encuentran sólido y seguro, sin nada que pueda objetarse. Transcripción del documento incluido en el Legajo 231. Archivo Municipal de Badajoz.
\end{abstract}

De Badajoz a diez y nueve de Abril de mil ochocientos cuarenta y tres: ante el Sr. Alcalde primero Constitucional, parecieron los peritos Pedro Rodríguez y Antonio Brazas, quienes bajo del cargo $\mathrm{q}^{\mathrm{o}}$ tienen aceptado y jurado, y de nuevo aceptan y juran caso necesario Dijeron: Que han reconocido con la mayor escrupulosidad y detenimiento las obras de reparación egecutadas [sic] en el Edificio Teatro de esta Capital, las cuales han encontrado hechas con toda solidez y seguridad no habiendo observado cosa $\mathrm{q}^{\mathrm{o}}$ pueda amenazar sin perjuicio conocido a los concurrentes a los espectáculos públicos que en dho [sic] edificio se representen. Que así es la verdad en descargo de sus juramentos hechos en el que y esta su declaración leída que les fue, se afirmaron y ratificaron y la firmaron con rúbrica de que certifico $=$ Pedro Rodrigz. Rúbrica. Antonio Brazas Galán. Rúbrica.

Recibido el 16 de enero de 2020.

Aceptado el 20 de abril de 2020. 